\title{
Radiobiology, Omics and Microdosimetry of Systemic and Targeted Radiotherapeutics Workshop
}

Approved for public release. Distribution is unlimited.

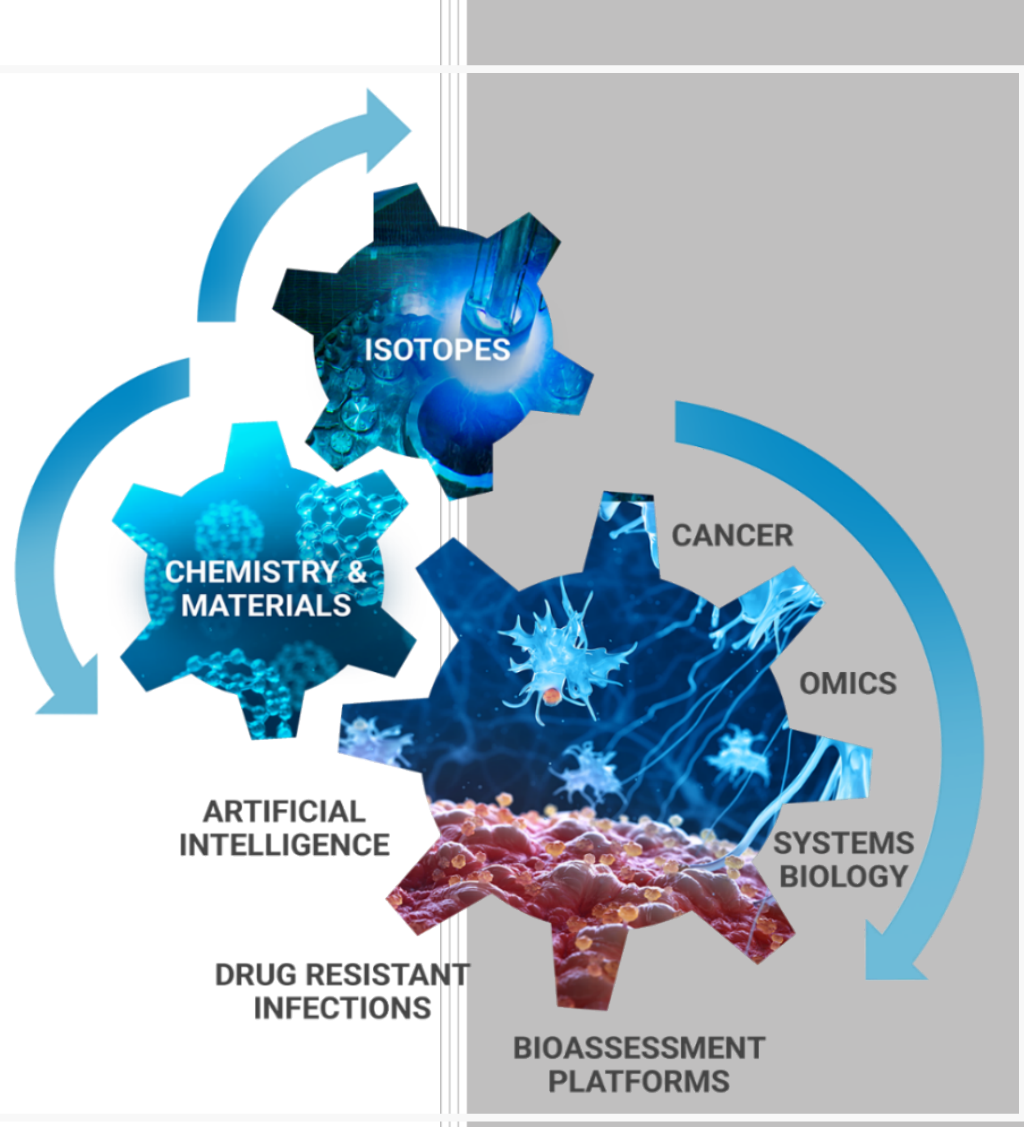

Sandra Davern Saed Mirzadeh

February 2020 


\title{
DOCUMENT AVAILABILITY
}

Reports produced after January 1, 1996, are generally available free via US Department of Energy (DOE) SciTech Connect.

Website www.osti.gov

Reports produced before January 1, 1996, may be purchased by members of the public from the following source:

\author{
National Technical Information Service \\ 5285 Port Royal Road \\ Springfield, VA 22161 \\ Telephone 703-605-6000 (1-800-553-6847) \\ TDD 703-487-4639 \\ Fax 703-605-6900 \\ E-mail info@ntis.gov \\ Website http://classic.ntis.gov/
}

Reports are available to DOE employees, DOE contractors, Energy Technology Data Exchange representatives, and International Nuclear Information System representatives from the following source:

Office of Scientific and Technical Information

PO Box 62

Oak Ridge, TN 37831

Telephone 865-576-8401

Fax 865-576-5728

E-mail reports@osti.gov

Website http://www.osti.gov/contact.html

This report was prepared as an account of work sponsored by an agency of the United States Government. Neither the United States Government nor any agency thereof, nor any of their employees, makes any warranty, express or implied, or assumes any legal liability or responsibility for the accuracy, completeness, or usefulness of any information, apparatus, product, or process disclosed, or represents that its use would not infringe privately owned rights. Reference herein to any specific commercial product, process, or service by trade name, trademark, manufacturer, or otherwise, does not necessarily constitute or imply its endorsement, recommendation, or favoring by the United States Government or any agency thereof. The views and opinions of authors expressed herein do not necessarily state or reflect those of the United States Government or any agency thereof. 
ORNL/TM-2020/1597

Isotope and Fuel Cycle Technology Division

\title{
Radiobiology, Omics and Microdosimetry of Systemic and Targeted Radiotherapeutics Workshop
}

held July 24-25, 2019, in support of the

\section{Accelerating Radiotherapeutic Innovations and Applications (ARIA) Initiative}

\section{Organizers}

Sandra Davern, and Saed Mirzadeh, Isotope and Fuel Cycle Technology Division, ORNL

\section{Discussion Leader}

\author{
Sandra Davern
}

\section{Speakers}

Neeta Pandit-Taskar, John Humm, and Sarah Cheal, Memorial Sloan Kettering Cancer Center Deborah Ramsey, CFD Research Corporation Jack Cahill, Miguel Toro Gonzalez, and Benjamin Doughty, ORNL Zachary Houston, University of Queensland, Australia

Volker Wagner, Bayer Pharmaceuticals

Rebecca San Martin, Jacob Sanders, and Rebecca Golloshi, UT Knoxville Robert Hobbs, Johns Hopkins University, Baltimore

Ravi Patel and Reinier Hernandez, University of Wisconsin, Madison

Patrick Causey, Canadian Nuclear Laboratories, Canada

Rebecca Abergel, University of California, Berkeley/Lawrence Berkeley National Laboratory Ekaterina Dadachova, University of Saskatchewan, Canada Charles Gawad, St. Jude Children's Research Hospital, Memphis Chris Wang, Georgia Institute of Technology, Atlanta Brian Lee, Northwestern University, Evanston, Illinois

\section{Scribes and Editors}

Emily Huckaby and Vj Ewing

Prepared by

OAK RIDGE NATIONAL LABORATORY

Oak Ridge, TN 37831-6283

managed by

UT-BATTELLE, LLC

for the

US DEPARTMENT OF ENERGY

under contract DE-AC05-00OR22725 



\section{CONTENTS}

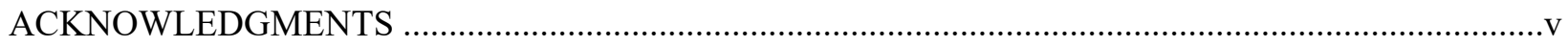

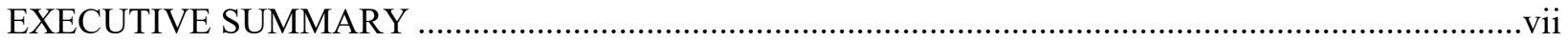

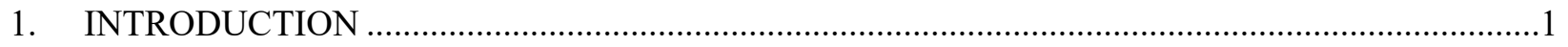

2. MOTIVATIONS AND CHALLENGES IN RADIOTHERAPEUTIC DEVELOPMENT ..................3

3. TRANSLATING RADIATION EFFECTS AT THE MOLECULAR AND CELLULAR LEVEL WITHIN THE TUMOR MICROENVIRONMENT FOR IMAGING, TARGETING, DOSIMETRY, AND IMMUNE ACTIVATION

4. TOOLS FOR ASSESSING MOLECULAR INTERACTIONS AND SINGLE-CELL OMICS POTENTIAL APPLICATIONS FOR UNDERSTANDING THE MECHANISM OF ACTION AND DOWNSTREAM EFFECTS OF TARGETED RADIOTHERAPY

5. NOVEL TARGETING TECHNIQUES AND ISOTOPE CONTAINMENT PLATFORMS FOR RADIONUCLIDE DELIVERY. . .13

APPENDIX A. AGENDA RADIOBIOLOGY, OMICS, AND MICRODOSIMETRY OF SYSTEMIC AND TARGETED RADIOTHERAPIES. A-1 APPENDIX B. WORKSHOP PARTICIPANTS. B-1 



\section{ACKNOWLEDGMENTS}

Oak Ridge National Laboratory would like to thank the speakers and those who attended the Workshop on Radiobiology, Omics and Microdosimetry of Systemic and Targeted Radiotherapies that was held at the laboratory July 24-25, 2019. Your contributions were essential to identifying the opportunities and challenges of radiotherapeutic therapy research and development. Thank you for participating in this crossdisciplinary format and collaborating with others in areas of research that may not be directly related to your specific field of expertise. We hope you agree that this meeting was productive and furthered our insights and understanding of the role of radiobiology, omics, and microdosimetry in radiotherapeutic development.

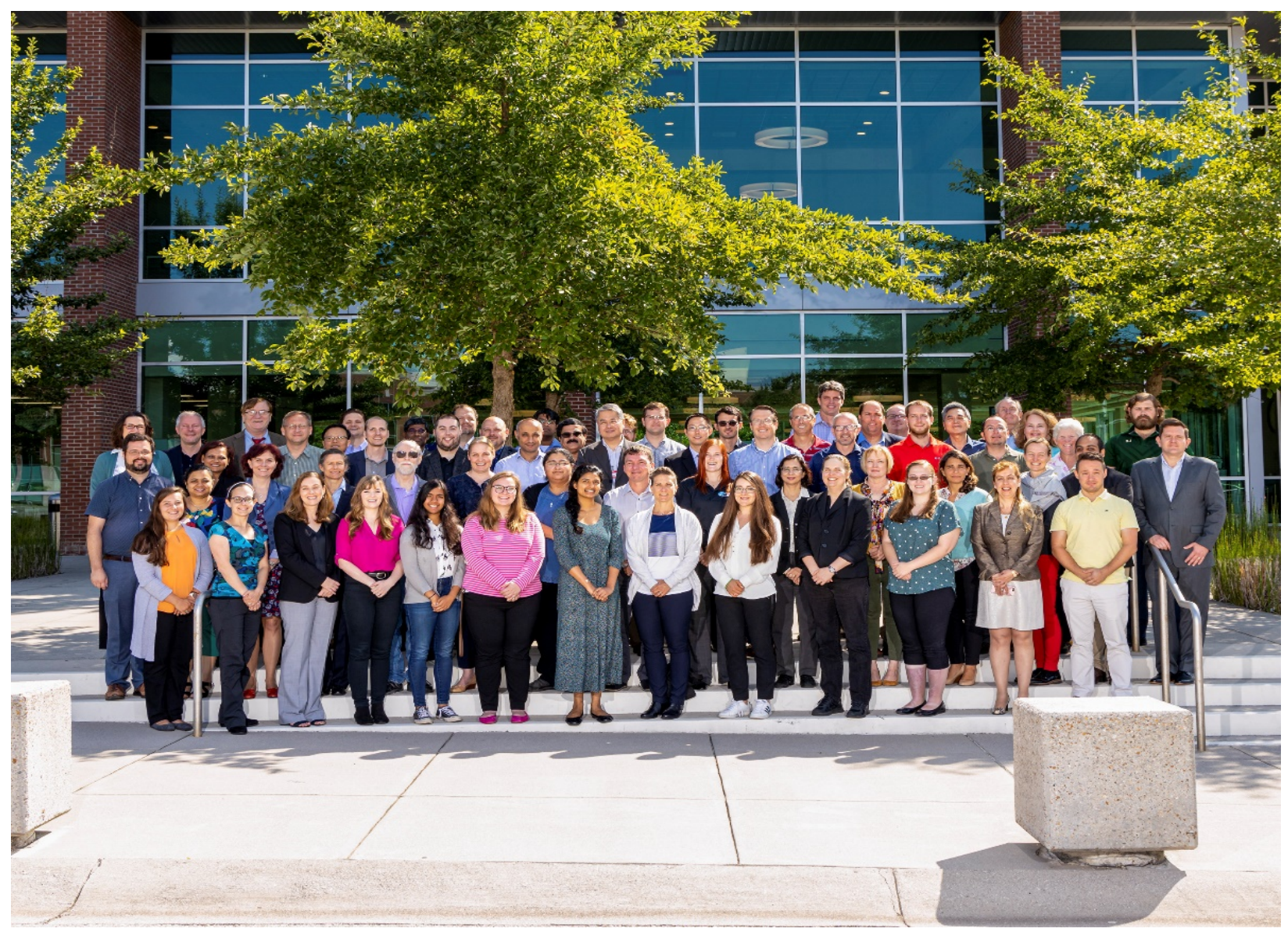

Radiobiology, Omics and Microdosimetry of Systemic and Targeted Radiotherapies Workshop participants 



\section{EXECUTIVE SUMMARY}

The Radiobiology, Omics and Microdosimetry of Systemic and Targeted Radiotherapeutics Workshop fostered engagement across disciplines on critical topics that impact the development of targeted radionuclide therapies, bringing together scientific and medical professionals actively involved in radiotherapeutic design, optimization testing, patient treatment, and clinical trials along with basic science researchers, whose novel techniques have the potential to further our understanding of targeted radionuclide therapy. Discussion of the applications of radiotherapeutics to pediatric and adult, brain, prostate and blood cancers, and metastatic disease allowed scientific research to be presented in the context of real-world medical applications and provided an important backdrop to the basic research performed in computers, laboratories, and animal facilities. The workshop format, presentations, and panel discussions were designed to consider a holistic approach to the development of systemic and targeted radiotherapies, integrating radiobiology and microdosimetry, biological assessments on the microscale, and physiologically relevant models of tumor and tissue microenvironments. Important needs highlighted in the workshop include better models to assess the biological effects of radionuclide therapy, novel strategies to target radiotherapeutics to disease sites with high specificity, and new dosimetry techniques that address the importance of tumor microenvironments.

Better model systems are needed to test the direct and indirect biological consequences of alpha-, beta- and Auger-emitting isotopes. Workshop participants discussed incorporation of in vitro models that move beyond standard two-dimensional single-cell-type formats to more complex organoids and organ-on-a-chip platforms which recreate physiologically relevant snapshots of human tumors and normal tissue. These model systems allow for interrogating the cellular and molecular effects of radiotherapeutics in the context of a three-dimensional environment that combines multiple cell types with their extracellular matrix and associated gravitational and or dynamic forces. These 3D model systems allow for imaging, omics, and microdissection of the individual effects of targeted drugs, nanoparticles, and radioisotopes; are uniquely suited to single-cell genomic and proteomic evaluation; and could readily be compared with data from patient-derived tissue samples. One drawback of these in vitro models, however, is that they lack the ability to mimic the influence of immune cells on responses of the microenvironment to radiation. The role of the immune system and the potential for a vaccination effect resulting from radionuclide therapy were discussed, highlighting the importance of adaptive immunity and T-cell populations in tumor microenvironments. Applying these new techniques and technologies will lead to a more comprehensive understanding of the molecular and cellular impacts of radiopharmaceuticals. The use of animal models and transitioning from mice to companion animals and non-human primates were viewed as important steps for moving to clinical trials. Increasing application in patient populations at curative rather than palliative timepoints will require a more comprehensive understanding of the acute and chronic impacts of these treatments.

Novel targeting strategies to increase accumulation and retention of parent isotopes and decay daughters at the target site offer opportunities to maximize dose to the tumor while minimizing dose to normal tissue and organs. Pre-targeting offers an elegant delivery mechanism which allows the accumulation of bispecific antibodies at the tumor site that is followed by administration of the a hapten (chelated isotope) that offers high tumor accumulation with fast renal clearance of the unbound isotope. Alternative strategies employ the use of nanoparticles to encapsulate and retain both parent and decay daughters at the tumor site, thereby maximizing the destructive impact of all the isotopes in the decay chain and minimizing off-target effects due to freely circulating isotopes. The application of nanoparticle technology for chemotherapeutics was also discussed. This technology offers opportunities for future combination therapies, considering radionuclide targeting and delivery focused on the appropriate selection and pairing of specific nuclides based on their half-lives (ranging from minutes to days) and pairing these with antibodies, peptides or small molecules to match circulation times and potentially design better therapeutics. 
Traditional dosimetry calculations have been established based on external beam radiation therapy and are being adapted to systemically targeted radionuclide therapy. A unique consideration in this situation is the heterogeneous distribution of dose within tumors, tissues, and organs. The traditional percent injected dose per gram of tissue does not accurately reflect "hot" and "cold" areas within the same tumor or organ and may require reevaluation of specific dose thresholds and standardized reporting for radionuclide therapies. The off-target distribution of decay daughters that escape the treatment site and circulate within the body is another factor that needs to be addressed. The application of computational models for microdosimetry and nanodosimetry will be important for determining relative biological effectiveness. Presentation and discussion of these issues underlined their central importance in the adoption of any radionuclide therapeutic. In the context of dosimetry, much discussion focused on the need for more involvement by scientific organizations and federal agencies in promoting education and training for medical professionals and scientists who work in these areas. Critical needs were identified for the delivery and distribution of these radiopharmaceuticals and their administration by trained professionals at community-level treatment centers.

Overall, this workshop highlighted the importance of integrating radiobiology, microdosimetry, omics, nanotechnology, and the tumor microenvironment to inform the development of systemic and targeted radiotherapies. The workshop pointed to the interest in development of these radioisotopes for medical applications by the scientific, medical communities, and the pharmaceutical industry and emphasized the importance of isotope supply and distribution to meet growing demands. Engaging in a cross-disciplinary environment enabled consideration of the challenges and opportunities of radionuclide therapies and promoted the integration of ideas, technologies, and techniques to advance radiotherapeutic innovations and applications. 


\section{INTRODUCTION}

\section{Applying modern omics techniques to systemic radiotherapy development and understanding}

The use of alpha and beta emitters for targeted radiotherapy and the potential applications of Auger emitters were discussed within specific disease paradigms. The short pathlengths and localized high-energy deposition of emitted alpha or beta particles from radioisotopes make them ideal candidates in the treatment of diseases such as cancer. Approval in 2013 of the first alpha emitter, Xofigo $\left({ }^{223} \mathrm{RaCl}_{2}\right)$, by the Food and Drug Administration (FDA) for bone pain palliation and its potential further use as a therapeutic agent show increasing acceptance by the public and a demand by the medical community for radiotherapeutic agents. In a move toward radioisotopes for precision medicine, the FDA more recently approved Lutathera (Lutetium, ${ }^{177} \mathrm{Lu}$, dotatate), a targeted therapy in which the beta emitter ${ }^{177} \mathrm{Lu}$ is attached to dotatate, an octapeptide that mimics natural somatostatin and binds somatostatin receptors on neuroendocrine tumors.

The focus of this workshop was on how modern omics techniques can be used to help understand the microdosimetry and biological consequences of bystander and abscopal effects within cells, tissues, and organs. Overall this workshop aimed to expand our knowledge of how the underlying biological effects of these treatments will impact a more widespread acceptance and integration of systemic and targeted radiotherapies in treatment regimens for cancer, as well as explore the potential of targeted radiotherapy for diseases such as drug-resistant infections.

The overarching goals of this workshop were (1) to discuss current data on the biology, physics, and microdosimetry of systemic and targeted radiotherapies and (2) to evaluate the benefits of a holistic approach to radiotherapeutic development centered on integrating cross-disciplinary research that expands our understanding of the biological consequences of these treatments at a cellular and molecular level.

Topics for discussion included the following.

- Identify the state of the art of systemic and targeted radiotherapies

- Evaluate the importance of studying tumor and normal organ microenvironments in the development of radiotherapies

- Explore the value of radiobiology and microdosimetry and our understanding of the biological effects of radiotherapies

- Examine the role of novel targeting techniques and nanotechnology for radioisotope delivery to target sites 
The format of this workshop was designed to encourage cross-disciplinary conversations that spark the imagination and promote new ideas and potential collaborations (Figure 1). Workshop sessions are typically organized according to silos of knowledge, with specialists debating among themselves the incremental and substantive developments applicable to their unique expertise. In contrast, the format of this workshop fostered discussion across disciplines and provided scientists and medical professionals from diverse backgrounds the opportunity to share knowledge and ideas relevant to the development and understanding of radiotherapeutics. The workshop consisted of three main sessions roughly themed around specific disease states, novel targeting strategies, tumor microenvironment, and microdosimetry-both modeling and empirical analyses. Each session was followed by panel discussions led by the speakers with questions and comments from the audience. 


\section{MOTIVATIONS AND CHALLENGES IN RADIOTHERAPEUTIC DEVELOPMENT}

The emerging use of radioisotopes for therapeutic applications presents an enormous opportunity for growth in the field of medical isotopes. Medical imaging agents, such as fluorine-18 (F-18) and technetium-99m (Tc-99m), are known for their diagnostic imaging properties. The increasing use of alpha and beta emitters to treat cancer is gaining wider attention by the medical community and the general public. Therefore, furthering our understanding of the dosimetry, microdosimetry, and biological consequences of these new cancer therapeutics is warranted. Integrating radiotherapeutics into patient treatment regimens requires a thorough understanding of their effectiveness, side effects, and downstream impacts - acute and chronic. It will necessitate combination treatments that incorporate current chemotherapy, hormone therapy, immunotherapy, external beam irradiation therapy and targeted radionuclide therapy. Improved targeting of tumors and delivery of radionuclides, combined with an understanding of tumor microenvironment and immune activation effects of radionuclide therapy, have the potential to positively impact patient outcomes.

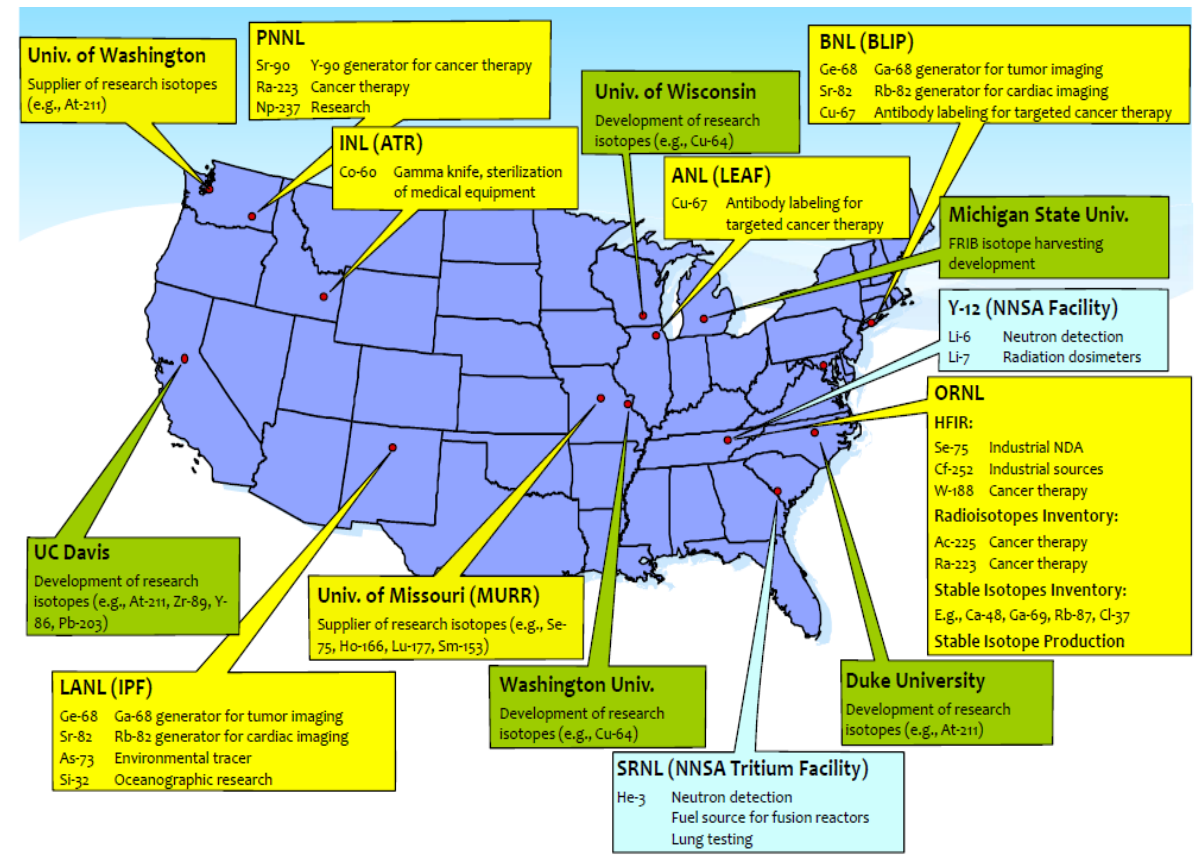

Figure 2. Department of Energy isotope production in the United States.

Under the direction of the Department of Energy Isotope Program, Oak Ridge National Laboratory (ORNL), along with other national laboratories and universities including Brookhaven, Los Alamos, and Pacific Northwest national laboratories and the University of Missouri Research Reactor, has a key role in the production of radioisotopes for medical imaging and therapeutics (Figure 2). Understanding the applications of these isotopes for cancer treatment, their integration into standard patient care, and their potential growth as combination therapies is essential to effectively meet the growing demand for these products and to develop technologies that enhance their safety and efficacy. Recognition of these developments in the field of radioisotope research and radiotherapy applications led us to propose a workshop at ORNL on the radiobiology, omics, and microdosimetry of targeted and systemic radiotherapeutics. This workshop was part of a wider initiative aimed at accelerating radiotherapeutic 
innovations and applications (ARIA) at ORNL, and it provided an opportunity to discuss related opportunities and challenges.

Challenges associated with the development of radiopharmaceuticals include the following.

- Retention of radionuclides and their decay daughters at the treatment site

- Understanding the tumor microenvironment in the context of radiotherapy

- Appropriate model systems to bridge the knowledge gap between pre-clinical and clinical studies

- Radioimmunotherapy applications beyond cancer

- Computational models for dosimetry and microdosimetry

- Supply and availability of radioisotopes to meet projected demand

- Distribution of radiopharmaceuticals

- Education, training, and safety for scientists and physicians 


\section{TRANSLATING RADIATION EFFECTS AT THE MOLECULAR AND CELLULAR LEVEL WITHIN THE TUMOR MICROENVIRONMENT FOR IMAGING, TARGETING, DOSIMETRY, AND IMMUNE ACTIVATION}

The development of radionuclide-based therapeutic agents for integration into standard regimens for the treatment of cancer and potential applications to treat drug-resistant infectious disease requires a holistic examination of their effects on a cellular and molecular level. The research presented over this 2-day workshop spanned the development, use, application, and understanding of radiopharmaceuticals/ radiotherapeutics from bench to bedside. From real-world patient studies, to pre-clinical findings and cellbased in vitro models, to computation and modeling of dosimetric effects, translating the impact of radionuclides for medical applications is not a trivial endeavor. The presentations and discussions central to this workshop underline the benefits of an integrated approach to radiotherapeutic development that further our understanding of therapeutic efficacy and associated biological consequences.

Key elements of the panel discussions included the following.

- $\quad$ Tumor Targeting

- Compartmentalized Treatment

○ Pre-targeting

○ Nanoparticles

- Multi-modal Therapies

- Therapeutic Index and Maximum Tolerated Dose

- Tumor Microenvironment (TME) and Optimizing Radiopharmaceutical Targeting

- Effects of Chemotherapy and External Beam Radiation Therapy (EBRT) on the TME

- Radiopharmaceutical Targeting Post Conventional Therapies (Chemotherapy and EBRT)

- Animal models, in vitro models and clinical trials

- Computational Models and Relative Biological Dose (RBE)

○ Dosimetry, Microdosimetry, and Nanodosimetry

- Organ, Cell, Organelle, and DNA Level Effects

- Radiobiology

- Bulk and Single-Cell Genomics and Proteomics

- Radiopharmaceuticals to Treat Cancer

- Immune Activation

- Combination Therapies

- Radiopharmaceuticals to Treat Infectious Disease

- Multi-Drug Resistance and Biofilms

- Reservoirs of Disease

- Isotope Availability and Scale-up to Meet Expanding Applications

- Role of Radio-Oncology Societies, Federal Agencies, and Drug Companies

- Regulation and Safety

$\circ$ Education and Training

Much of our understanding of targeting radionuclides to tumor sites is based on imaging studies in which fast clearance of high-affinity targeting molecules is beneficial. However, in the context of radiotherapies, longer residence times at the treatment site increases the effective dose and improves the therapeutic index (TI). Because considerable research has centered on the development of small targeting molecules such as peptides and single-chain variable fragment ( $\mathrm{scFv}$ ) molecules for imaging applications, these have been tested for therapeutic applications. However, it is important to both image and treat the cancer cells, which means it is necessary to consider the different time scales relevant to each of these processes. The fast clearance rate desirable for imaging agents does not always translate to a useful therapeutic agent. Using 
whole antibodies for longer circulation and increased target accumulation within the tumor is one approach, but there is also a trend toward modifying small targeting molecules with larger molecules such as albumin to extend their circulation time. Achieving the correct balance between circulation time and tumor accumulation is essential. In addition, Dr. Pandit-Tasker suggests that it is critical to recognize that not only can the type and size of a targeting molecule be changed but also the type of isotope bound to this molecule. Both of these elements will alter the biodistribution and toxicity of the radiopharmaceutical. Smaller molecules will be excreted through the kidneys, giving rise to potential renal toxicities, while larger molecules exert greater toxicity to the bone marrow. Potentially optimizing and balancing the biodistribution of targeting molecules with combinations of alpha- and beta-emitting radionuclides offer the "potential to target not only bulky tumors but also micrometastases," according to Dr. Pandit-Tasker. This "cocktail of molecules" may offer the greatest therapeutic effect.

Pre-targeting radioimmunotherapy (PRIT), as discussed in Dr. Cheal's presentation, offers great potential for optimizing the TI and increasing the maximum tolerated dose (MTD) while minimizing the dose to normal tissues. In this situation a Proteus whole antibody construct is targeted to the tumor site and allowed time to accumulate. This construct is developed by combining scFv moieties that will bind a radionuclideDOTA-Bn hapten when subsequently administered. An important intermediate clearance step ensures that there is minimal circulating antibody, and therefore any unbound radionuclide (Lu-177 or Ac-225) is rapidly cleared through the kidneys. Given the enormous potential of this pre-targeting strategy, there was much discussion on the radiosensitivity of specific cancer targets given that studies have shown extremes in radiosensitivity with neuroblastoma models requiring $\sim 30 \mathrm{~Gy}$ and colorectal tumors models 100 Gy to obtain curative responses. The properties of the antibody itself, internalizing or non-internalizing, are important for achieving an optimal TI, with the non-internalizing antibodies demonstrating better TIs. Balancing all these factors, along with optimizing the timing of administration of the different components, will be crucial to optimizing this strategy. Overall, this novel targeting strategy clearly offers great potential for optimized radiopharmaceutical applications.

In discussing the benefits of this approach, the concept of theranostics was also addressed, acknowledging the benefits of real-time imaging of the biodistribution of the therapeutic radionuclide. Further consideration of the tumor microenvironment and the consequences of previous treatments on antigen expression and immune activation were highlighted. Translating the information obtained from pre-clinical models to patient clinical trials is a knowledge gap that needs further study. Here the contributions of more physiologically accurate in vitro models were discussed. If the aim is identifying novel targets and producing better targeting agents, then more complex model systems offer the potential for better personalized medicine strategies that can lead to the identification of conventional therapeutic regimens for individual patients. This approach recognizes the challenge of both tumor heterogeneity and normal tissue complexity. Organ-on-a-chip systems offer the potential to model some of these variables and facilitate a better understanding of the biological effects at the cellular level. This has the potential to bridge the species gap beyond moving from mice to non-human primates since biodistribution in humans is a recognized challenge. One aspect of the TME that is not easily adapted to in vitro models is the immune system, and this is seen as a limitation of these models. Complex in vitro models offer unique test platforms for toxicity testing and should be integrated into the toolkit for drug design and development to enhance our understanding of potential in vivo toxicities and expedite the approval process for new pharmaceuticals.

Theranostics offers the opportunity to both image and treat in one modality and to visualize exactly where the therapeutic agent has been delivered. Many patients who go into clinical trials have been heavily pretreated with EBRT and chemotherapy resulting in scarring and rearrangement of the TME, which is potentially very different from current model systems. As observed by Dr. Houston's study of canine companion animals, EBRT can dramatically affect the blood brain barrier and therefore impact the delivery of theranostic and conventional imaging agents. EBRT can make tissues leaky, but their toxicities are usually designed to avoid damage to the bone marrow and kidneys. Therefore, there is great potential for 
combination therapies that include radioimmunotherapy and EBRT without overlapping toxicity profiles. The current standard of care offers something like Lu-177 dotatate after EBRT; however, it may be more beneficial to reverse this treatment strategy. Since pre-irradiation (EBRT) increases tissue leakiness and often results in elimination or decreased expression of the target antigen, it may be more beneficial to treat with the radiopharmaceutical first.

Drs. Humm and Hobbs both discussed the importance of dosimetry in the context of treatment planning and dose optimization for specific tumors and organs. Recognizing that all treatments are becoming multimodal, the need for accurate dosimetry models is essential. To date, organ toxicities are based on EBRT data, and the currently accepted limits of 2 Gy to the marrow is not completely accurate when applied to the administration of Xofigo ${ }^{\circledR}$ (Ra-223 dichloride), for example. In some instances, this results in doses of $\sim 4.5 \mathrm{~Gy}$ to the bone marrow, and the resultant lack of toxicity is due to the non-uniform dose distribution associated with this therapy. Similarly, in the case of kidney toxicity, standard toxicity limits for EBRT have been established for a long time and are very controlled. However, for radiopharmaceuticals "the distribution and the uptake in the relative regions of each organ depends on the radiopharmaceutical that's being given," according to the Drs. Humm and Hobbs. There are fundamental differences between EBRT and radiopharmaceuticals with "physiology rather than geometry of the beam" driving the dose and "microlocalization giving rise to different dose average thresholds," even between different radiopharmaceuticals. Dr. Hobbs suggests that it is not unreasonable to consider dose escalation studies for every radiopharmaceutical to estimate their specific dose threshold. Standardization is required for dose reporting to help inform current dosimetry models. When considering the relative biological effectiveness (RBE) for alpha and beta radiopharmaceuticals, it is essential to consider not only the absorbed dose but also the dose rate, and standardizing reporting will help determine differences due to physiological uptake. Dose limitation to vital organs such as the liver and the spleen must be determined when evaluating the MTD for different radiopharmaceuticals. It was suggested that we should consider "defining dose by toxicity," similar to the rationale for chemotherapeutics. This approach may allow for higher MTDs at the tumor site with acceptable overall organ toxicities, but it must be discussed in the context of what the FDA will approve and the requirement that dose escalation studies be performed to show clinical benefit.

The roles of federal agencies, drug companies, and scientific societies were discussed as they will have a considerable impact on the socialization, acceptance, and regulation of radiopharmaceuticals going forward. The American Society for Radiation Oncology (ASTRO) and the Society for Nuclear Medicine and Molecular Imaging (SNMMI) are collaborating to help further the development of radiopharmaceutical therapy. They are working to implement, as a medium-term strategy, absorbed dose treatment planning by bringing together the radiation oncologists, physicists, and nuclear medicine experts who understand and have expertise with dose administration and calculations. Collaboration between the National Cancer Institute (NCI), National Institutes of Health (NIH), FDA, Nuclear Regulatory Commission (NRC), and drug companies will be essential for building momentum to move toward absorbed-dose-based treatment planning. Additional discussions focused on the need for training of physicians and medical physicists on the handling and administration of these new radiopharmaceuticals if they are to be more widely used to treat cancer patients, especially at community sites. Currently, radiation oncologists do not always get certified to deliver radioisotopes. These issues are recognized and are being addressed by ASTRO and the SNMMI and the American Association of Physicists in Medicine (AAPM) who are focused on retrospective training as well as establishing task groups. Another identified group that requires training in the use of radionuclides are biochemists, as these are the people who necessarily perform the preclinical work that drives new products toward clinical trials. It is important that they too have an understanding of dosimetry. It was generally agreed that the United States needs to be cognizant of training the next generation of physicians and scientists, so as not to fall behind in this area.

In his presentation on the application of Ac-225 to treat prostate cancer, Dr. Causey from Canadian Nuclear Laboratories touched on the fact that they are now also producers of Ac-225 and have a Th-229 generator 
sufficient for small-scale studies in Canada. The supply and availability of all alpha- and beta-emitting radioisotopes for medical applications was a major concern of the audience and given all of the potential applications of these different isotopes, the mechanism for determining the rate of scale-up and production. The DOE Isotope Program and the National Isotope Development Center are responsible for the production of isotopes such as Ac-225, Bi-213, Ac-227, Pb-212, Th-228, Th-227, and others. Regarding the factors that influence their production, Dr. Balkin from DOE headquarters discussed the availability of many of these isotopes and on current strategies for expansion and production, including the submission of two drug master files (DMFs) to the FDA for the production of Ac-225 by natural decay of Th-229 and as a spallation product of irradiated Th-232.

The influence of systemic radiotherapy on immune cell activation was discussed in light of Dr. Patel's presentation on the ability of low-dose systemic radiotherapy, using ${ }^{90} \mathrm{Y}-\mathrm{NM} 600$, to transform immunologically cold tumors and generate a T-cell mediated immune response. Here the T-cells show clonal expansion as detected by cell sequencing but not increased receptor diversity. These studies even indicated that immune memory was established, with complete-response mice exhibiting no tumor growth upon rechallenge. The dose relationship effect of alpha, beta, and Auger emitters was discussed in relation to EBRT, and it was suggested that alpha therapy could play a greater role in the earlier stages of disease in bulky tumors with minimal metastatic disease. These studies could reveal a positive synergy between the tumor immune response and radiation therapy; however, the opposite also needs to be considered since studies with EBRT indicate that larger irradiation fields and longer irradiation times result in lymphopenia. Radiation dose that dramatically decreases T-cell populations is likely to have an adverse outcome since it would prevent an immunological response. As previously established, the tumor microenvironment is critical to our understanding of the effects of these radiotherapies both in regard to cellular infiltrate populations and cytokine response profiles. Similarly, Dr Hernandez's work on targeting a non-Hodgkin's lymphoma model with ${ }^{90} \mathrm{Y}$-NM600 showed curative responses and immunological memory mediated by Tcells that prevent tumor growth upon rechallenge. This rechallenge phenomenon was also observed for the targeted thorium conjugate therapy (TTC) treatment investigated by Dr. Wagner and colleagues from Bayer Pharmaceutical.

The effectiveness of targeted radiotherapy to treat bacterial, fungal, and viral infectious disease was discussed by Dr. Dadachova, from the University of Saskatchewan, Canada. The application of targeted radiotherapy to treat infectious disease is a unique and important departure from conventional cancer treatment. With the rise in drug-resistant infections and the pronounced side effects associated with standard-of-care therapies, alternative treatments are needed. Radioimmunotherapy allows selective targeting of infectious agents to destroy the pathogen itself, and by extension, irradiating and destroying host cells contribute to positive outcomes. This therapy can be used for treating microbial biofilms that are resistant to antibiotics such as Methicillin-resistant Staphylococcus aureus (MRSA) infections, has applications for prosthetic joint infections, and can be applied to target reservoirs of disease as occurs in HIV infections. Here residual disease often resides in the brain, making it inaccessible to conventional retroviral therapy and leading to cognitive decline in these patients. Understanding the dosimetry and biological consequences of these therapies on an organ, cellular, and molecular level will advance their acceptance by the medical professional who lacks a background in nuclear medicine.

Assessing DNA damage on the microscale was the central theme in a number of presentations that examined the effects of radiation on three-dimensional chromosomal structure, the potential to apply single-cell genomics to radiation-treated cell populations, and the use of computational models to assess the differential effects of alpha, beta and Auger emitters on cell targets. In summary, the main method of cell death is via DNA double strand breaks (DSBs), but additional effects associated with membrane permeability and the production of reactive oxygen species in the cellular milieu should also be considered, especially when assessing potential abscopal and bystander effects. The greater potential of alpha particles to induce DSBs that result in cell death is why they are effective for cancer. Increased computational power and modeling 
capabilities that can be applied to individual cell structures, such as nuclear structure, DNA, organelles, and cell membranes need to be applied to gain a better understanding for the RBE for radiopharmaceuticals. 


\section{TOOLS FOR ASSESSING MOLECULAR INTERACTIONS AND SINGLE-CELL OMICS POTENTIAL APPLICATIONS FOR UNDERSTANDING THE MECHANISM OF ACTION AND DOWNSTREAM EFFECTS OF TARGETED RADIOTHERAPY}

One of the goals of this workshop was to introduce new technologies to the field of radiotherapeutic development that could further our understanding for the mechanism of action of these therapies alone or in combination with conventional therapies. The field of omics research covers a broad range of areas, including genomics, metabolomics, proteomics, transcriptomics etc., and to date has mostly yielded information on bulk responses or effects observed for multiple cells and in complex tissue environments. Recent advances have focused on applications that can quantify effects at the single-cell level and have the potential to aid in the identification of cells that will develop resistance or have become resistant to chemical, hormone, or radiation treatment. A number of presentations on developments in the area of single-cell omics research were integrated with studies highlighting complex in vitro biological platforms to study cancer and normal tissue microenvironments. Combining these novel technologies with the application of computational models of dosimetry at the cellular level offers opportunities to enhance our understanding of systemic radiotherapies.

Technical advances in the field of single-cell genomics have ramped up in recent years. Methods to improve this technology are evolving, and at Dr. Gawad's laboratory at St. Jude's Children's Research Hospital, these advances have specifically focused on primary-template-directed single-cell whole genome amplification (PTA) to enable accurate detection to $\sim 85 \%$ of genetic variation in each individual cell. This emerging technology has shown a step increase in its application over the past 10 years, and highlighting it at this workshop will promote its potential to better understand the consequences of radiopharmaceutical therapy on normal organ and tumor microenvironments. Because most of our knowledge of genomics come from bulk analysis of mixtures of cells, tissue-level measurements that look for individual variation on a cell-to-cell basis have until recently been beyond our capabilities. With the advent of single-cell genomics, tissue heterogeneity and the influence of external factors can be investigated. Regarding the study of radiation therapy and radiopharmaceuticals, this technology can help inform our knowledge of the cells within a tumor that develop resistance and identify potential alterations to normal tissue that could lead to the development of aberrant cells.

As part of this discussion, Dr. Cahill from ORNLs Chemical Sciences Division gave a unique perspective on single-cell assessment within a specific disease or normal microenvironment using single-cell printer technology and liquid vortex capture-mass spectrometry (SCP-LVC-MS). Here he introduced the concept of resolving cellular omics (genomics, epigenomics, transcriptomics, proteomics, metabolomics, etc.) on the single-cell scale using proof-of-concept research in microalgae. This technique has the potential to expand research beyond just bulk analysis of cellular environments, where the average may not adequately represent the function of individual cells. The application of this concept when considering resistance to therapy in cancer patients has the potential to design patient specific treatment strategies. More specifically, it will be critical to eliminate the potential for radioresistance when including targeted radiotherapies in treatment regimens. Also discussed were the observed bystander effects of media derived from alpha particle irradiated cells where the media itself has cytotoxic effects. This is most likely due to the upregulation of a signaling molecule that is excreted into the media or perhaps the products of DNA damage excreted into the media. The abscopal effect, however, is most likely an immune response. Understanding single-cell effects may be more beneficial than bulk analysis.

Novel spectroscopic analysis using ultrafast dynamics as contrast, as presented by Dr. Doughty, has applications at cell-cell interfaces and, by extension, to cell-nanoparticle interactions. The capability to visualize chemical heterogeneity and obtain high-resolution images can go beyond the state of the art, which relies on staining or chemically treating samples to allow for label-free non-invasive imaging based on 
intrinsic molecular vibrational signatures. Applications of this new techniques would allow the study of living biological systems and could potentially be applied to cellular response to radioactive and nonradioactive nanoparticles (organic and inorganic), interactions with targeting antibodies or peptides, and potential membrane disruptions associated with radiation damage in real-time. Advances in this technology will offer unique perspectives on the impact of therapeutic interventions on the tumor microenvironment.

Current applications of radionuclides to treat prostate cancer focus on the use of Ra-223 as a palliative treatment of associated bone metastases and clinical trials using prostate-specific membrane antigen (PSMA) conjugated to Ac-225 or Th-227, for example. Therefore, the presentation by Dr. San Martin from the University of Tennessee, Knoxville, on the use of prostate organoid model to study the tumor microenvironment fit well within the scope of this workshop. In prostate cancer, a reactive stroma response is associated with tumor progression and unfavorable outcomes. The use of stroma-epithelial organoids to study the biology of the tumor microenvironment and the metastatic potential of these cells when co-cultured with mesenchymal stem cell (MSC)-derived osteogenic organoids or hydroxyapatitecoated scaffolds were presented. This research showed novel mechanisms of metastatic colonization and development. The organoid models presented here have potential applications to test the effects of chemotherapeutic or radionuclide drugs at the scale of the tumor microenvironment.

Further investigation of novel in vitro model systems for evaluating radiobiological effects in normal and tumor microenvironments included a presentation given by Dr. Ramsey from CFD Research Corporation on the development and application of a Synthetic Blood Brain Barrier in vitro model (SynBBB). This model system mimics the critical three-dimensional microenvironment of the neurovascular unit with multiple cell types, anatomical size constraints, and shear stress conditions. The SynBBB model was developed to assess functional transport of molecules across the blood brain barrier to gain a better understanding of the mechanism of action of therapeutic screening molecules. Applying the SynBBB platform to the study of targeted radiotherapeutics has the potential to expand our knowledge of the ontarget and off-target effects of these agents through molecular imaging and off-chip genomic and proteomic analysis. The opportunity to work with lower cell and reagent volumes is another attractive feature of this technology that should work well in assessing the biological consequences of radiotherapeutics.

Combining the need for microenvironment assessment of the cellular effects of radiotherapeutics in patient and in physiologically relevant in vitro models is a central idea of this workshop. Thus, integrating the dosimetry of alpha and beta particles into this cellular environment is integral to our understanding of their impact on a molecular and cellular level. Dr. Humm from Memorial Sloan Kettering Cancer Center discussed the importance of microdosimetry in targeted alpha radionuclide therapy. Dr. Humm highlighted the importance of understanding the microdistribution of alpha emitters within tissue, providing specific examples of radium-223, which elementally targets bone, and actinium-225, complexed to targeting antibodies for delivery to soft-tissue tumors, given the short range of $\alpha$-particles in tissue $(<90 \mu \mathrm{m})$ and the targeted high local energy deposition which corresponds with effects on biological targets such as cell membranes, nuclei and DNA. Incorporating whole organ uptake with histological and autoradiographic analysis is helping to guide a more comprehensive knowledge of the local distribution within organs and tissues. How these analyses could be considered in the context of the tumor microenvironment and human in vitro model systems was covered in panel discussions and included the potential role of proteomic analysis in these analyses.

Matching available isotopes to suitable targeting molecules and chelators was also addressed. It was suggested that isotopes such as $\mathrm{Bi}-213$ are well matched to targeting peptides that have rapid clearance rates. A recognized issue with $\mathrm{Bi}-213$ is the large quantities required for treatment, approximately 100 times greater than the equivalent dose of Ac-225. Lead-212 as a substitute for the Bi-213 was discussed, but there are some issues associated with ligand retention of the energetic beta. Further discussion of the importance to chelator research was led by Dr Abergel, from Berkeley University/Lawrence Berkeley National 
Laboratory. She referenced standard chelators like 1,4,7,10-tetraazacyclododecane-1,4,7,10-tetraacetic acid (DOTA) and diethylenetriaminepentaacetic acid (DTPA) along with the 18-membered macrocycle (Macropa), each of which is optimal for different isotopes. Therefore, the choice of chelator must be matched to the isotope and the application. However, more research to develop better chelators is necessary to move the field forward.

In incorporating in vitro model systems, single-cell analytical techniques with microdosimetry and nanodosimetry will be useful when examining the effects of radionuclides in cellular microenvironments. Dr. Wang and Dr. Lee gave an overview of the field of microdosimetry and nanodosimetry, looking at how these analyses inform the evolution of radiobiological modeling. Their research focused on the development of models based on GEANT for DNA that model dosimetry of cellular and DNA damage associated with exposure to alpha, beta, gamma and Auger radiation.

Students Jacob Sanders and Rosella Golloshi, from Dr. Patton McCord's laboratory at the University of Tennessee, Knoxville, gave a presentation on the effects of radiation and mechanical deformation on chromosome three-dimensional structure using Hi-C analysis and modeling, which provides a more specific understanding of chromosomal deformation effects. Their presentation increased our awareness of the basic research that is being conducted at the university and contributed to our understanding of the long-term consequences of successfully treating patients with radionuclides. Alterations at the chromosomal level and epigenetic changes in DNA may have long-term and potentially heritable consequences that deserve consideration. 


\section{NOVEL TARGETING TECHNIQUES AND ISOTOPE CONTAINMENT PLATFORMS FOR RADIONUCLIDE DELIVERY}

The delivery of radioisotopes to specific sites of cancer or disease is an essential component of targeted radiotherapy. Our understanding of many currently approved radionuclide therapies relies on their elemental targeting to select biodistribution sites (e.g., I-131 to thyroid and Ra-223 to bone). These types of therapies, though effective, have limited applications. The ability to selectively target radionuclides to tumor-specific antigens or other recognition moieties is essential to making these therapies more universally applicable. Attaching the radionuclide to targeting molecules, such as monoclonal antibodies, antibody fragments, peptides, etc., overcomes the issues of elemental biodistribution and facilitates selective delivery to cancer cells throughout the body. Radionuclides such as Ac-225 and Lu-177 are metal ions that require confinement within cage-like chelator structures such as the 1,4,7,10-tetraazacyclododecane-1,4,7,10tetraacetic acid (DOTA) molecule. Radium-223 can be chelated and trapped by molecular cages such as crown-ether-based chelators like calixarene; however, this entrapment cannot be adequately retained in vivo, making targeting of this radionuclide untenable.

A number of presentations focused on the importance of targeting, including Dr. Cheal from Memorial Sloan Kettering Cancer Center, Dr. Houston from The University of Queensland, Dr. Abergel from Berkeley University/Lawrence Berkeley National Laboratory, and Dr. Toro Gonzalez from ORNL, who each presented on novel technologies and techniques to target, deliver, and retain radionuclides for therapeutic, diagnostic, and theranostic applications. Dr. Cheal discussed her research on pre-targeted alpha- and beta-radioimmunotherapy. Specifically, she discussed the use of a series of novel antitumor/anti-DOTA hapten bispecific antibodies (bsAb) for pre-targeted radioimmunotherapy (PRIT). This technology takes advantage of the development of anti-metal chelate antibodies that recognize the DOTALu-177 or DOTA-Ac-225 chelated radionuclide. Here a bispecific antibody is initially administered to target the tumor antigen; this is followed by clearance of non-tumor bound BsAb using a dextran-based clearing agent and finally administration of the chelated radiometal (Lu-177 or Ac-225). The small size of the chelated-radiometal allows for rapid renal clearance, which decreases toxicity to normal tissue and maximizes dose at the target site. These very effective studies exhibit curative responses, and the overall methodology shows great promise for adaptation to patients.

Radionanoparticle research at ORNL has focused on the development of inorganic nanoparticles for the encapsulation and retention of radionuclides and their decay daughters. Dr. Gonzalez presented data on the multifunctional properties of these nanoparticles for combined imaging and therapeutic applications as well as in vitro cytotoxicity assays in two-dimensional and in three-dimensional tumor cell platforms. Optimizing radionanoparticle synthesis and characterization for isotopes such as Ac-225, Ra-223, and Th227 was discussed. Initial work on the application of organic nanoparticles to retain surrogate metal salts was also discussed by comparing organic and inorganic carriers of radionuclides in three-dimensional highthroughput screening platforms for cytoxicity and radiation effects. Similarly, the use of polymeric nanomedicines for theranostic applications that combines fluorescence, magnetic, photoacoustic, and radioactive imaging modalities to inform cancer treatments was addressed. The use of a hyperbranched polymeric theranostic nanoparticles model for delivery of chemotherapeutics was presented by Dr. Houston from the University of Queensland.

A summary of the important characteristics of metal ion chelators, highlighting further considerations associated with the biological targeting molecule, was given by Dr. Abergel from Berkeley University/Lawrence Berkeley National Laboratory. Her presentation showed the diversity of chelators available and the importance of the immunocongugate design for avoiding toxicity while maximizing therapeutic efficacy by comparing the beta emitter Lu-177 and the alpha emitter Ac-225 in vivo. Her presentation highlighted potential theranostic applications and the requirement for new chelators to enable 
the chelation of multifunctional isotopes. Similar to multifunctional imaging and therapeutic applications in nanoparticle research, this method offers potential benefits for short-lived isotopes and imaging relative to when longer-lived isotopes with multiple alpha decay products that are recalcitrant to chelation would be more appropriate for nanoparticle encapsulation and immunoconjugation. 


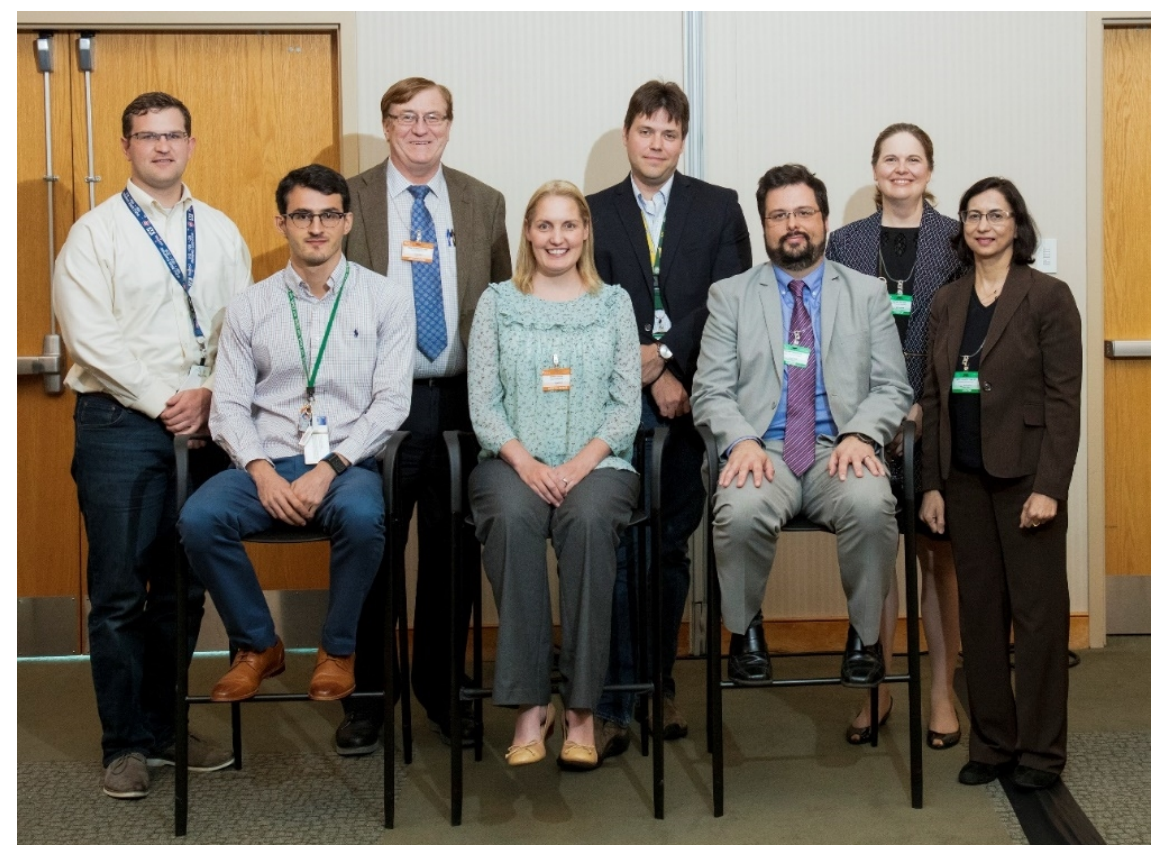

Session 1 Speakers and Panelists

Left to Right: Jack Cahill, Miguel Toro-Gonzalez, John Humm, Sarah Cheal, Benjamin Doughty, Zach Houston, Deborah Ramsey, and Neeta Pandit-Tasker

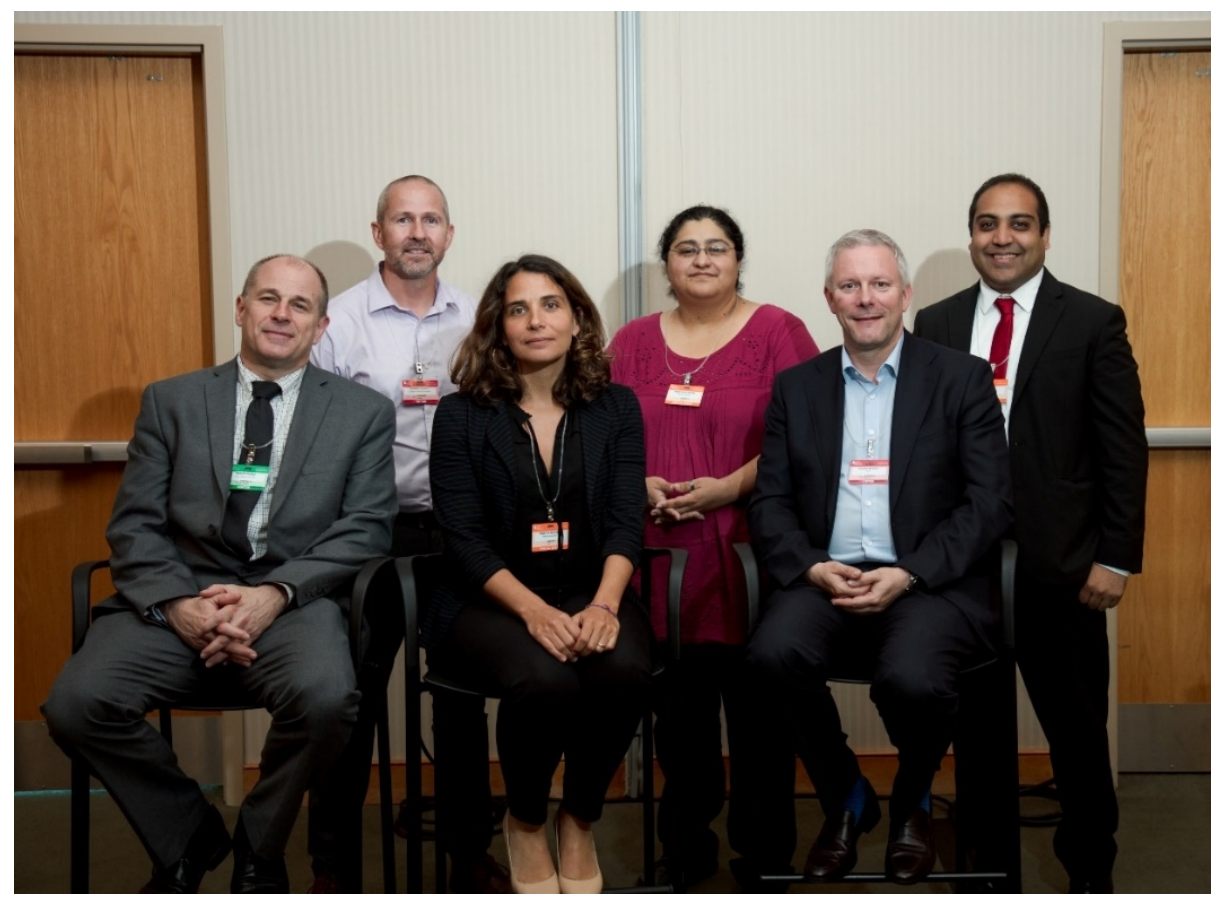

Session 2 Speakers and Panelists

Left to Right: Robert Hobbs, Patrick Causey, Rebecca Abergel, Rebecca San Martin, Volker Wagner, and Ravi Patel 


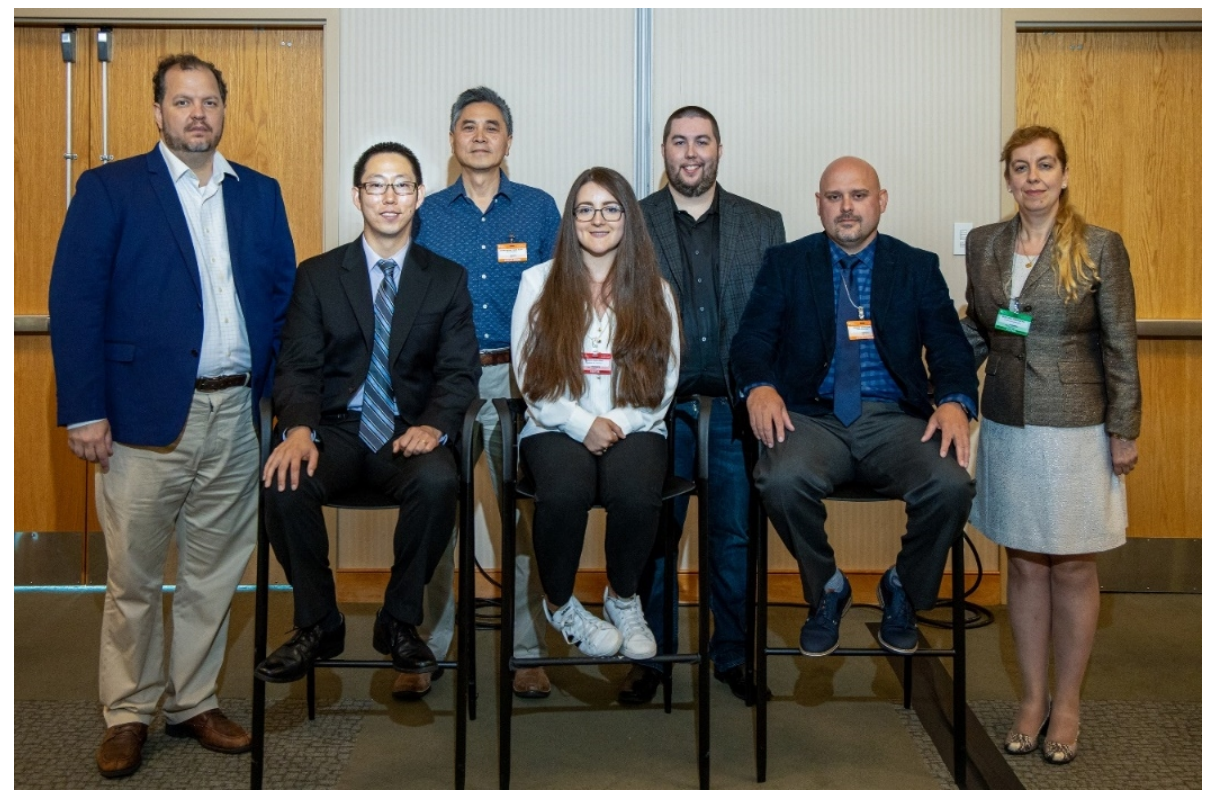

Session 3 Speakers and Panelists

Left to Right: Charles Gawad, Brian Lee, Chris Wang, Rosella Golloshi, Jacob Sanders, Reinier Hernandez and Ekaterina Dadachova 



\section{APPENDIX A. AGENDA RADIOBIOLOGY, OMICS AND MICRODOSIMETRY OF SYSTEMIC AND TARGETED RADIOTHERAPIES}

\begin{tabular}{|c|c|c|c|c|}
\hline Event contact & \multicolumn{4}{|c|}{$\begin{array}{l}\text { Sandra Davern, 865-576-6709 (office); 865-719-1059 (mobile); davernsm@ornl.gov } \\
\text { Kim Ryan, 865-574-8008 (office); 865-679-6998 (mobile); ryanka@ornl.gov }\end{array}$} \\
\hline Time & Event & Lead & Attendees & Place \\
\hline \multicolumn{5}{|c|}{ Wednesday, July 24, 2019} \\
\hline $8: 00-8: 30 \mathrm{am}$ & Welcome and Introductory Remarks & $\begin{array}{l}\text { Michelle Buchanan } \\
\text { Sandra Davern }\end{array}$ & All & $\begin{array}{l}\text { Building } 5200 \\
\text { Tennessee Rooms }\end{array}$ \\
\hline 8:30-9:00 am & $\begin{array}{l}\text { Novel Agents and Techniques for } \\
\text { Theranostics and Tumor } \\
\text { Microenvironment Assessment }\end{array}$ & Neeta Pandit-Taskar & All & $\begin{array}{l}\text { Building } 5200 \\
\text { Tennessee Rooms }\end{array}$ \\
\hline $9: 00-9: 25 \mathrm{am}$ & $\begin{array}{l}\text { Syn-BBB: A Physiologically Relevant } \\
\text { Blood Brain Barrier (BBB) Model for } \\
\text { Functional Transport and Therapeutic } \\
\text { Screening }\end{array}$ & Deborah Ramsey & All & $\begin{array}{l}\text { Building } 5200 \\
\text { Tennessee Rooms }\end{array}$ \\
\hline $9: 25-9: 50 \mathrm{am}$ & $\begin{array}{l}\text { The Importance of Microdosimetry in } \\
\text { Targeted Alpha-Radionuclide Therapy }\end{array}$ & John Humm & All & $\begin{array}{l}\text { Building } 5200 \\
\text { Tennessee Rooms }\end{array}$ \\
\hline $9: 50-10: 15$ am & \begin{tabular}{|l|} 
Rapid, Untargeted Profiling of Single \\
Cells Using Single-Cell Printer-Liquid \\
Vortex Capture-Mass Spectrometry \\
\end{tabular} & Jack Cahill & All & $\begin{array}{l}\text { Building } 5200 \\
\text { Tennessee Rooms }\end{array}$ \\
\hline $10: 15-10: 40 \mathrm{am}$ & Break & & All & $\begin{array}{l}\text { Building } 5200 \\
\text { Tennessee Rooms }\end{array}$ \\
\hline $10: 40-11: 05 \mathrm{am}$ & $\begin{array}{l}\text { Pre-Targeted Alpha-Radioimmunotherapy } \\
\text { of Solid Tumors using DOTA-PRIT }\end{array}$ & Sarah Cheal & All & $\begin{array}{l}\text { Building } 5200 \\
\text { Tennessee Rooms }\end{array}$ \\
\hline $11: 05-11: 30 \mathrm{pm}$ & $\begin{array}{l}\text { Polymer Theranostics as Vehicles for } \\
\text { Biologically Inspired Design of } \\
\text { Nanomedicines in Preclinical and } \\
\text { Comparative Oncology }\end{array}$ & Zach Houston & All & $\begin{array}{l}\text { Building } 5200 \\
\text { Tennessee Rooms }\end{array}$ \\
\hline $11: 30-11: 55$ am & $\begin{array}{l}\text { Evaluating Lanthanide-Based and } \\
\text { Poly(lactic-co-glycolic acid) } \\
\text { Nanoparticles toward Theranostics from } \\
\text { Material Science and Biological } \\
\text { Perspectives }\end{array}$ & Miguel Toro Gonzalez & All & $\begin{array}{l}\text { Building } 5200 \\
\text { Tennessee Rooms }\end{array}$ \\
\hline $11: 55-12: 20 \mathrm{pm}$ & \begin{tabular}{|l|} 
Imaging Complex Systems Using \\
Ultrafast Dynamics as Contrast \\
\end{tabular} & Ben Doughty & All & $\begin{array}{l}\text { Building } 5200 \\
\text { Tennessee Rooms }\end{array}$ \\
\hline $12: 20-1: 00 \mathrm{pm}$ & Panel Discussion & \begin{tabular}{lll|}
$\begin{array}{l}\text { Presenters will lead } \\
\text { discussion }\end{array}$ & \\
\end{tabular} & All & $\begin{array}{l}\text { Building } 5200 \\
\text { Tennessee Rooms }\end{array}$ \\
\hline $1: 00-2: 00 \mathrm{pm}$ & $\begin{array}{l}\text { Working Lunch: } \\
\text { Overview of the DOE Isotope Program }\end{array}$ & Kevin Hart & All & $\begin{array}{l}\text { Building } 5200 \\
\text { Tennessee Rooms }\end{array}$ \\
\hline $2: 00-2: 35 \mathrm{pm}$ & $\begin{array}{l}\text { Overview of the Development of } \\
\text { Targeted Alpha Therapies, PSMA-TTC } \\
\text { and Xofigo (Ra-223), for Prostate Cancer } \\
\text { and Metastases }\end{array}$ & Volker Wagner & All & $\begin{array}{l}\text { Building } 5200 \\
\text { Tennessee Rooms }\end{array}$ \\
\hline
\end{tabular}




\begin{tabular}{|c|c|c|c|c|}
\hline Event contact & \multicolumn{4}{|c|}{$\begin{array}{l}\text { Sandra Davern, 865-576-6709 (office); 865-719-1059 (mobile); davernsm@ornl.gov } \\
\text { Kim Ryan, 865-574-8008 (office); 865-679-6998 (mobile); ryanka@ornl.gov }\end{array}$} \\
\hline Time & Event & Lead & Attendees & Place \\
\hline \multicolumn{5}{|c|}{ Wednesday, July 24, 2019} \\
\hline $2: 35-3: 00 \mathrm{pm}$ & $\begin{array}{l}\text { In Vitro 3D Modeling of the Reactive } \\
\text { Tumor Microenvironment in Prostate } \\
\text { Cancer: A Resource for Pathophysiology } \\
\text { Discovery and Therapeutics Development }\end{array}$ & Rebecca San Martin & All & $\begin{array}{l}\text { Building } 5200 \\
\text { Tennessee Rooms }\end{array}$ \\
\hline $3: 00-3: 25 \mathrm{pm}$ & $\begin{array}{l}\text { Small-Scale Modeling and Dosimetry for } \\
\text { Radiopharmaceutical Therapy of Prostate } \\
\text { Cancer }\end{array}$ & Rob Hobbs & All & $\begin{array}{l}\text { Building } 5200 \\
\text { Tennessee Rooms }\end{array}$ \\
\hline $3: 25-4: 00 \mathrm{pm}$ & Afternoon Break & & All & $\begin{array}{l}\text { Building } 5200 \\
\text { Tennessee Rooms }\end{array}$ \\
\hline 4:00-4:25 pm & $\begin{array}{l}\text { Utilization of Targeted Radionuclide } \\
\text { Therapy to Enhance Efficacy of Cancer } \\
\text { Immunotherapy }\end{array}$ & Ravi Patel & All & $\begin{array}{l}\text { Building } 5200 \\
\text { Tennessee Rooms }\end{array}$ \\
\hline $4: 25-4: 50 \mathrm{pm}$ & $\begin{array}{l}\text { Targeted Alpha Therapy: A Platform } \\
\text { Technology as Applied for Treatment of } \\
\text { Prostate Cancer }\end{array}$ & Pat Causey & All & $\begin{array}{l}\text { Building } 5200 \\
\text { Tennessee Rooms }\end{array}$ \\
\hline $4: 50-5: 15 \mathrm{pm}$ & $\begin{array}{l}\text { Correlating Biological Effects to } \\
\text { Molecular Damage in Targeted Alpha- } \\
\text { Therapy }\end{array}$ & Rebecca Abergel & All & $\begin{array}{l}\text { Building } 5200 \\
\text { Tennessee Rooms }\end{array}$ \\
\hline $5: 15-6: 00 \mathrm{pm}$ & Panel Discussion & $\begin{array}{l}\text { Presenters will lead } \\
\text { discussion }\end{array}$ & All & \begin{tabular}{|l|} 
Building 5200 \\
Tennessee Rooms \\
\end{tabular} \\
\hline 6:00 pm & Depart Lab for Hotel & & All & \\
\hline $6: 30 \mathrm{pm}$ & $\begin{array}{l}\text { Dinner Seminar: Development of a Novel } \\
\text { Radiotracer for Imaging Systemic } \\
\text { Amyloidosis }\end{array}$ & Jon Wall & All & $\begin{array}{l}\text { Double Tree Hotel } \\
215 \quad \text { S. Illinois } \\
\text { Avenue }\end{array}$ \\
\hline
\end{tabular}




\begin{tabular}{|c|c|c|c|c|}
\hline Event contact & \multicolumn{4}{|c|}{$\begin{array}{l}\text { Sandra Davern, 865-576-6709 (office); 865-719-1059 (mobile); davernsm@ornl.gov } \\
\text { Kim Ryan, 865-574-8008 (office); 865-679-6998 (mobile); ryanka@ornl.gov }\end{array}$} \\
\hline Time & Event $\dagger$ & Lead & Attendees & Place \\
\hline \multicolumn{5}{|c|}{ Thursday, July 25, 2019} \\
\hline $8: 00-8.30 \mathrm{am}$ & Introductory Remarks & Marti Head & All & $\begin{array}{l}\text { Building } 5200 \\
\text { Tennessee Rooms }\end{array}$ \\
\hline $8: 30-9: 10 \mathrm{am}$ & $\begin{array}{l}\text { Radioimmunotherapy of Systemic } \\
\text { Infections }\end{array}$ & Kate Dadachova & All & $\begin{array}{l}\text { Building } 5200 \\
\text { Tennessee Rooms }\end{array}$ \\
\hline $9: 10-9: 40 \mathrm{am}$ & $\begin{array}{l}\text { [90Y]Y-NM600 Targeted Radionuclide } \\
\text { Therapy Affords Complete Response and } \\
\text { Immunologic Memory in Models on T- } \\
\text { Cell Non-Hodgkin's Lymphoma }\end{array}$ & Reinier Hernandez & All & $\begin{array}{l}\text { Building } 5200 \\
\text { Tennessee Rooms }\end{array}$ \\
\hline 9:40-10:00 am & $\begin{array}{l}\text { Radiation-Induced DNA Damage Effects } \\
\text { on Chromatin Architecture }\end{array}$ & Jacob Sanders & All & $\begin{array}{l}\text { Building } 5200 \\
\text { Tennessee Rooms }\end{array}$ \\
\hline 10:00-10:20 am & $\begin{array}{l}\text { 3D Genome Organization Changes } \\
\text { Associated with Melanoma Confined } \\
\text { Migration }\end{array}$ & Rosela Golloshi & All & $\begin{array}{l}\text { Building } 5200 \\
\text { Tennessee Rooms }\end{array}$ \\
\hline 10:20-11:00 am & Break & & All & $\begin{array}{l}\text { Building } 5200 \\
\text { Tennessee Rooms }\end{array}$ \\
\hline 11:00-11:30 am & $\begin{array}{l}\text { Dissecting Tissue-Environment } \\
\text { Interactions with Single-Cell Genomics }\end{array}$ & Charles Gawad & All & $\begin{array}{l}\text { Building } 5200 \\
\text { Tennessee Rooms }\end{array}$ \\
\hline $11: 30-12: 30 \mathrm{pm}$ & $\begin{array}{l}\text { Microdosimetry, Nanodosimetry, and } \\
\text { Radiobiological Modeling } \\
\text { (Joint Presentation) }\end{array}$ & $\begin{array}{l}\text { Chris Wang } \\
\text { Brian Lee }\end{array}$ & All & $\begin{array}{l}\text { Building } 5200 \\
\text { Tennessee Rooms }\end{array}$ \\
\hline $12: 30-1: 00 \mathrm{pm}$ & Panel Discussion & \begin{tabular}{|l} 
Presenters will lead \\
discussion
\end{tabular} & All & $\begin{array}{l}\text { Building } 5200 \\
\text { Tennessee Rooms }\end{array}$ \\
\hline $1: 00-2: 00 \mathrm{pm}$ & $\begin{array}{l}\text { Working Lunch: } \\
\text { Current Isotope Production and R\&D } \\
\text { Efforts at ORNL }\end{array}$ & Roy Copping & All & $\begin{array}{l}\text { Building } 5200 \\
\text { Tennessee Rooms }\end{array}$ \\
\hline $2: 00-6: 00 \mathrm{pm}$ & $\begin{array}{l}\text { ORNL Tours (optional) } \\
\text { High Flux Isotope Reactor } \\
\text { Radiochemical Engineering Development } \\
\text { Center (Hot Cells) } \\
\text { Graphite Reactor } \\
\text { Center for Nanophase Material Sciences } \\
\text { Spallation Neutron Source } \\
\text { Summit Supercomputer } \\
\text { Biosciences Laboratories }\end{array}$ & & All & ORNL Tour Hosts \\
\hline $6: 00 \mathrm{pm}$ & Adjourn & & All & Depart ORNL \\
\hline
\end{tabular}

$\uparrow$ The Center for Nanophase Material Sciences and the Spallation Neutron Source are colocated at the same site on the ORNL campus. The High Flux Isotope Reactor and the Radiochemical Engineering Development Center (Hot Cells) are colocated at the same site. The Graphite Reactor, supercomputing facilities, and biosciences laboratories are on the main ORNL campus. 



\section{APPENDIX B. WORKSHOP PARTICIPANTS}

ORNL

Marti Head, Director-Joint Institute of Biological Sciences

Kenneth Tobin Jr, Director of Institutional Planning

Kevin Hart, Isotopes Program Manager-Isotope Chemistry

Bart Iddins, Division Director-Health Services Division

Benjamin Lewis Jr, Interim Division Director-Isotope and Fuel Cycle Technology Division

Julie Mitchell, Division Director-Biosciences Division

Rose Boll, Group Leader-Medical, Industrial and Research Isotopes

Roy Copping, Group Leader-Nuclear and Radiochemistry

Mitchel Doktycz, Group Leader-Biological and Nanoscale Systems

Dan Stracener, Group Leader-RIB Experimental Systems

Greeshma Agasthya, Research Scientist-Bioengineering and Health Information

Zane Bell, Sr. Radiation Detection Researcher-Radiation, Detection and Imaging

Paul Benny, Sr. R\&D Scientist-Medical, Industrial \& Research Isotopes

Jack Cahill, R\&D Associate-Mass Spectrometry and Laser Spectroscopy

Joseph Conner, Technical Specialist-In vitro Dosimetry

Sandra Davern, Radioisotope Researcher-Nuclear and Radiochemistry

Ben Doughty, R\&D Scientist-Mass Spectrometry and Laser Spectroscopy

Justin Griswold, Nuclear Science Staff Member-Nuclear and Radiochemistry

Richard Leggett, Scientist, Dosimetry Research-Society, Energy \& Environment

Madhavi Martin, Research Staff-Metabolomics Group

Amber McBride, Staff Scientist-Molecular Biology, Microbial Ecology and Physiology

Saed Mirzadeh, Scientist-Nuclear Medicine, Nuclear and Radiochemistry

Jennifer Morrell-Falvey, Research Staff-Biological and Nanoscale Systems

John Neal, Senior R\&D Staff-Isotope and Fuel Cycle Technology Division

Allison Peacock, Radiochemical Technician-Nuclear and Radiochemistry

Caleigh Samuels, R\&D Assistant Staff Member-Society, Energy \& Environment

Manasi Balachandran, Postdoctoral Research Associate-Systems Genetics

Miguel Toro Gonzalez, Postdoctoral Fellow-Nuclear and Radiochemistry

ORNL Students and Visiting Faculty

Viktor Bautista, Texas A\&M University, Graduate Student

Anna George, East Tennessee State University, Undergraduate Student

Mehnaz Haque, Georgia Institute of Technology, Undergraduate Student

Felicite Noubissi, Jackson State University, Faculty Member

Dimitri Margot, Texas A\&M University, Graduate Student

Mikyla Molnar, University of Illinois, Graduate Student

Sadhana Venkataraman, Purdue University, Undergraduate Student

Bayer Pharmaceuticals

Volker Wagner, Vice President

Petra Kramer, Clinical Development Leader

BWXT

Amelia Adelsperger, Biomedical Engineer

Canadian Nuclear Laboratories

Pat Causey, Research Scientist

Denise Gendron, Radiochemical Technologist 
Randy Perron, Radiochemical Technologist

Cardinal Health

Olga Koper, Senior Director

Henry Padgett, Director of Chemistry Development

CFD Research Corporation

Fewell Gwenn, Chief Commercial Officer, SynVivo, Inc.

Balabhaskar Prabhakarpandian, Director, Biomedical and Life Sciences Division

Deborah Ramsey, Group Leader, Biomedical and Life Sciences Division

Cincinnati Children's Hospital

Mathieu Sertorio, Instructor

Clemson University

Nicole Martinez, Assistant Professor, Dept. of Environmental Engineering and Earth Sciences,

College of Engineering, Computing and Applied Sciences

Fusion Pharmaceuticals

Ryan Simms, Director of Chemistry

Georgia Institute of Technology

Nolan Hertel, Professor, Nuclear and Radiological Engineering

Chris Wang, Professor, Medical Physics

Johns Hopkins University

Robert Hobbs, Associate Professor

Memorial Sloan Kettering Cancer Center

John Humm, Vice Chair of Research, Service Chief of Molecular and X-Ray Imaging Physics, Departments of Medical Physics \& Radiology

Neeta Pandit-Taskar, Attending Radiologist, Molecular Imaging \&Therapy Svc, Dept of

Radiology. Clinical Director, Center for Targeted Radioimmunotherapy and Theranostics, Ludwig Center for Cancer Immunotherapy

Sarah Cheal, Senior Research Scientist, Dept of Molecular Pharmacology and Chemistry

National Isotope Development Center (NIDC)

Karen Sikes, Assoc. Director, Production Planning and Market Research

Ariel Brown, Quality Assurance Specialist

Northwestern University

Brian Lee, Assistant Professor of Radiation Oncology

Oak Ridge Associated Universities

Adayabalam Balajee, Director of Cytogenetic Biodosimetry Laboratory

Jason Davis, Radiation Emergency Assistance Center/Training Site, Health Physicist

St. Jude Children's Research Hospital

Charles Gawad, Assistant Member, St. Jude Faculty, Dept. of Oncology and Dept. of

Computational Biology

Texas A\&M University

Dmitri Margot, Graduate Student 
University of California, Berkeley, and Lawrence Berkeley National Laboratory

Rebecca Abergel, Assistant Professor

University of Iowa, Carver College of Medicine

David Bushnell, Professor of Radiology

University of Queensland, Australia

Viktor Vegh, Group Leader

David Reutens, Professor

Rajiv Bhalla, Associate Professor

Zach Houston, Postdoctoral Fellow

University of Saskatchewan, Silvia Fedoruk Center for Nuclear Innovation Chair in Radiopharmacy Ekaterina Dadachova, Professor

University of Tennessee

Steven Ripp, Associate Professor

Larry Millet, UT JIBS Faculty

Rebecca San Martin, Postdoctoral Fellow

Micholas Smith, Postdoctoral Fellow

Jacob Sanders, Graduate Student

Priyojit Das, Graduate Student

Rosella Golloshi, Graduate Student

Delany Thurston, Undergraduate Student

Trevor Freeman, Technician

University of Tennessee Graduate School of Medicine

Stephen Kennel, Professor

Ramchandren Radhakrishnan, Professor, Chief, Division of Hematology/Oncology

Jonathan Wall, Professor

Dustin Osborne, Associate Professor

Joseph Kelley, Assistant Professor, Radiation Oncology

University of Wisconsin

Steve Cho, Associate Professor of Radiology, Director - PET GMP Radiopharmaceutical

Production Facility (RPF), Director - UW Carbone Cancer Center Clinical Imaging Research Core (CRIC), Associate Director - UW PET Imaging center

Ravi Patel, Bentson Laboratory Research Fellow

Reinier Hernandez, Research Associate

Vanderbilt University

Jacob Houghton, Assistant Professor, Radiology and Radiological Sciences

Brandon Carney, Postdoctoral Fellow, Radiology and Radiological Sciences 
